\title{
Which Half Are You? Almost Half of Pediatric Oncologists and Intensivists Are Burnt Out......
}

\author{
K. Sarah Hoehn, MD, $M B e^{1}$ \\ Manjusha Abraham, MD2 \\ John Gaughan, $P h D^{3}$ \\ Brigham C. Willis, $M^{4}$
}

1Department of Pediatric Critical Care, University of Chicago Comer Children's Hospital, Chicago IL

${ }^{2}$ Department of Pediatrics, Section of Critical Care, St. Mary's Hospital, St Louis MO ${ }^{3}$ Biostatistics Consulting Center, Temple University School of Medicine, Philadelphia, PA

${ }^{4}$ Division of Cardiovascular Intensive Care, Department of Child Health, University of Arizona College of Medicine - Phoenix and Phoenix Children's Hospital, Phoenix, AZ

\begin{abstract}
Objective: To study the prevalence of burnout, secondary traumatic stress, and wellbeing among pediatric critical care and pediatric hematology and oncology physicians

Design: Observational cohort study

Setting: Online survey

Patients: Active American Academy of Pediatrics (AAP) members of the section of critical care and the section of hematology and oncology

Interventions: Surveys containing three validated instruments (the Maslach Burnout Inventory, the secondary traumatic stress scale and the Personal Wellbeing Index, as well as questions on demographics and lifestyle) were emailed out via the AAP. Measurements and Main Results: We had 231 respondents with a response rate of $15.8 \%$ among PICU physicians and $26.1 \%$ among hematology-oncology physicians. $45.9 \%$ of our participants consisted of hematology-oncology physicians and $54.1 \%$ of pediatric critical care physicians. The population was a balanced gender mix but was predominantly Caucasian ( $82 \%$ Caucasian and $10 \%$ Asian). The overall rate of burnout was $46.6 \%$ (47.8\% among hematology-oncology physicians and $45.8 \%$ among pediatric intensivists). We found significant rates of emotional exhaustion, with $43.0 \%$ of respondents scoring high on this subscale.
\end{abstract}

The prevalence of secondary traumatic stress was $46.8 \%$ (42.5\% among hematologyoncology physicians and $50.9 \%$ among pediatric intensivists). Physicians in practice over 10 to 15 years had significantly higher rates of secondary traumatic stress $(p<$ $0.05)$. No other demographic or lifestyle variable was significantly associated with an increased risk of burnout or secondary traumatic stress.

Conclusion: Our study reports concerning rates of burnout and secondary traumatic stress among pediatricians in the specialties of Hematology/Oncology and Pediatric Critical Care Medicine. The results raise concern for better screening and prevention for 
burnout in these high risk specialties. Promoting recognition of early symptoms is crucial, as well as creating a work environment that promotes mental health.

\section{Background}

For millennia, physicians have promised to take care of patients to the best of our abilities. In doing so, physicians make personal sacrifices and face challenging situations, including significant administrative burdens of the electronic medical record; all of which may contribute to burnout (1). This led to the AMA supporting a Charter of Physician Well Being, highlighting the importance of building resilience among physicians (2). The topic of physician burnout as one of the leading stories in 2017 (3). Physicians have a have a higher rate of burnout compared to US workers in other fields (4). Burnout has been defined as "a syndrome of emotional exhaustion and cynicism that occurs frequently among individuals who do 'people-work' of some kind" (5). Burnout syndrome has 3 key dimensions: emotional exhaustion, depersonalization and lack of personal accomplishment. These problems can affect not only physicians themselves but also patient care. Studies show that burnout is more common among physicians who are 11-20 years in practice (6). A German study suggests that female senior physicians having children are at the greatest risk for burnout (7).

Along with burnout, physicians may face post-traumatic stress. It has become increasingly more evident that trauma does not only affect the individual(s) directly involved, but also others around them, including healthcare workers. Thus, the concept of secondary traumatic stress has been defined. Secondary traumatic stress (STS) is defined as "the natural, consequent behaviors and emotions resulting from knowledge about a traumatizing event experienced by a significant other. It is the stress resulting from helping or wanting to help a traumatized or suffering person" (8). STS has been studied in a variety of caregiving populations, including social workers, nurses, chaplains, and child life specialists, but there is only limited to no data on STS among pediatric physicians (9-12).

In studying the prevalence of burnout and secondary traumatic stress among physicians, we would be remiss not to also assess the overall wellbeing of these individuals. Wellbeing is defined as "a relative state where one maximizes his or her physical, mental, and social functioning in the context of supportive environments to live a full, satisfying, and productive life". The measurement of wellbeing in all Americans is a Healthy People 2020 objective (13).

We used standardized instruments to assess the prevalence of burnout, the prevalence of secondary post-traumatic stress, and the overall wellbeing of high-risk pediatric physicians. We hypothesized that pediatric critical care physicians and pediatric hematology/oncology physicians would have similarly high rates of burnout, STS and adverse effects on overall wellbeing. 


\section{Methods}

The study was reviewed and approved by the Institutional Review Board of Kansas University Medical Center via expedited review. Four questionnaires (Maslach Burnout Scale, Secondary Traumatic Stress, Personal Wellbeing Index, demographic survey) were emailed to the section of critical care medicine and the section on pediatric hematology and oncology of the American Academy of Pediatrics. Reminders to complete the surveys were sent out at 4 and 6 weeks after the initial email. No identifiable data was recorded.

\section{Maslach Burnout Inventory (MBI)}

The Maslach Burnout Inventory (MBI) was developed to study burnout syndrome, and has 3 sub scales focusing on the areas of emotional exhaustion (EE), depersonalization (DP) and personal accomplishment (PA). It consists of 22 items on a questionnaire that uses a six point Likert scale (Appendix 1). A high degree of burnout is reflected by high scores on the emotional exhaustion and depersonalization scale in addition to low scores on the personal accomplishment scale. The MBI has been shown to have coefficient alpha between 0.70 to 0.80 in 84 different studies that used the MBI to assess burnout, indicating that the MBI has good internal consistency in low stakes testing (14). Since its initial publication in 1980, the MBI has been shown to adequately assess the presence or absence of burnout in a variety of physician groups (15-19). In our study we defined burnout as the presence of at least one of the following: $E E \geq 37$ or $\mathrm{DP} \geq 13$ or $\mathrm{PA}<31$ (15).

\section{Secondary Traumatic Stress Scale (STSS)}

The Secondary Traumatic Stress Scale (STSS) was developed by Bride and colleagues (20) by using the seventeen symptoms of post traumatic stress disorder from the DSMIV, and has seventeen items that are answered using a five point Likert type scale. It has been found to have an overall coefficient alpha of 0.94 . There are three subscales and each subscale has a coefficient alpha as well: intrusion, 0.80; avoidance, 0.87; arousal 0.79 .

\section{Personal Wellbeing Index (PWI)}

The Personal Wellbeing Index (PWI) scale contains 7 questions, each one addressing a quality of life domain: standard of living, achieving in life, health, relationships, safety, community-connectedness, and future security. In regards to reliability, the Cornbach alpha lies between 0.70 and 0.85 in Australia and overseas and the index has shown good test-retest reliability with an intra-class correlation coefficient of 0.84 (21).

\section{Demographic Survey}

The demographic questionnaire is a self-constructed survey with common factors (years in practice, hours of sleep at night, hours of exercise per week, healthy diet, marital status, number of children, religion) that can be associated as a risk versus protective factors for burnout, secondary traumatic stress and overall wellbeing. Each factor had a comment section for qualitative analysis. 
Data Analysis

Variables measured on a continuous scale are presented as means with standard deviations. Groups were compared using the Wilcoxon rank sum test and ANOVA on ranks. Categorical measurements are presented as frequencies with percentages. Groups were compared using Fisher's exact test and chi-square. A value of $<0.05$ was considered statistically significant. All analyses were carried out using SAS V9.2 statistical software (SAS Institute, Cary, NC).

\section{Demographics}

\section{Results}

Our study population consisted of 231 participants, in which hematology/oncology physicians and pediatric critical care physicians were evenly distributed $(45.89 \%$ vs $54.1 \%)$. Initially the study was sent out to 732 members of AAP section of pediatric critical care and 445 members of the AAP section of hematology and oncology. The response rate was $15.8 \%$ among PICU physicians and $26.1 \%$ among hematology and oncology physicians. We attribute our low response rate to the automated depersonalized email from a website, rather than individual requests to members. Surveys that were started but were determined to be incomplete were excluded. The population was gender balanced (female $51.8 \%$, male $48.2 \%$ ), but predominantly Caucasian. $82.5 \%$ identified themselves as Caucasian, $10.8 \%$ as Asian, $0.9 \%$ as African American and 5.8\% as others. With regard to religion more than half identified themselves as Christians (56.1\%) followed by $25.3 \%$ who chose not to specify their religion. $11.8 \%$ identified themselves as Jewish, $3.6 \%$ as Hindus and $3.2 \%$ as Muslims. Most of our participants (76.8\%) were married. $35.1 \%$ had 2 children followed by $22.1 \%$ who had no children. This study group mostly consisted of physicians who were $>20$ years in practice (40.6\%). $75.5 \%$ sleep 5-7 hours per night and $58.4 \%$ exercise $2-3$ times per week. Half of this group (53.1\%) claimed to consume a healthy diet (Table 12). 
Table 1. Demographic Characteristics $(\mathrm{n}=231)$

\begin{tabular}{|l|c|c|}
\hline Gender & $\mathbf{n}$ & $\%$ \\
\hline Male & 108 & 48.2 \\
\hline Female & 116 & 51.8 \\
\hline Race/Ethnicity & & \\
\hline Caucasian & 184 & 82.5 \\
\hline Asian & 24 & 10.8 \\
\hline Other & 13 & 5.8 \\
\hline African American & 2 & 0.9 \\
\hline Hispanic & 12 & 5.4 \\
\hline Hispanic & 211 & 94.6 \\
\hline Non-Hispanic & & \\
\hline Religious Afriliation & 124 & 56.1 \\
\hline Christian & 56 & 25.3 \\
\hline No Religious Afriliation & 26 & 11.8 \\
\hline Jewish & 8 & 3.6 \\
\hline Hindu & 7 & 3.2 \\
\hline Muslim & & \\
\hline Marital Status & 172 & 76.8 \\
\hline Married & 31 & 13.8 \\
\hline Single & 12 & 5.4 \\
\hline Divorced & 7 & 3.1 \\
\hline Partnered & 2 & 0.9 \\
\hline Widowed & & \\
\hline Number of Children & 49 & 22.1 \\
\hline $\mathbf{0}$ & 33 & 14.9 \\
\hline $\mathbf{1}$ & 78 & 35.1 \\
\hline $\mathbf{2}$ & 36 & 16.2 \\
\hline $\mathbf{3}$ & 13 & 5.9 \\
\hline $\mathbf{4}$ & 13 & 5.9 \\
\hline $\mathbf{5}$ or more & & \\
\hline Years in Practice & 14 & 6.3 \\
\hline $\mathbf{1 - 5}$ years & 44 & 19.6 \\
\hline $\mathbf{5 - 1 0}$ years & 34 & 15.2 \\
\hline $\mathbf{1 0 - 1 5}$ years & 41 & 18.3 \\
\hline $\mathbf{1 5 - 2 0}$ years & 91 & 40.6 \\
\hline$>\mathbf{2 0}$ years & & \\
\hline
\end{tabular}

Table 2. Habits $(n=231)$

\begin{tabular}{|l|c|c|}
\hline Hours of sleep & $\mathbf{n}$ & $\%$ \\
\hline$<3$ hours & 1 & 0.5 \\
\hline $\mathbf{3 - 5}$ hours & 16 & 7.1 \\
\hline $\mathbf{5 - 7}$ hours & 169 & 75.5 \\
\hline >7 hours & 38 & 17.0 \\
\hline Exercise & & \\
\hline 2-3x per week & 131 & 58.7 \\
\hline Once per week & 36 & 16.1 \\
\hline Once every 2 weeks & 22 & 9.9 \\
\hline Once a month & 19 & 8.5 \\
\hline Not at all & 15 & 6.7 \\
\hline Balanced diet & & \\
\hline Yes & 119 & 53.1 \\
\hline No & 24 & 10.7 \\
\hline Sometimes & 81 & 36.2 \\
\hline
\end{tabular}

Maslach Burnout Inventory

The overall burnout rate was $46.8 \%$ (45.8\% among pediatric critical care physicians and $47.8 \%$ among hematology/oncology physicians) (Table 3). 
Table 3: Comparison of burnout, secondary traumatic stress and wellbeing rates between pediatric critical care and hematology oncology physicians

\begin{tabular}{|c|c|c|c|}
\hline Variable & $\begin{array}{l}\text { Pediatric critical care } \\
\text { physicians } N(\%)\end{array}$ & $\begin{array}{l}\text { Hematology oncology } \\
\text { physicians } N(\%)\end{array}$ & p \\
\hline Overall rate of burnout & $54(45.8)$ & $54(47.8)$ & 0.80 \\
\hline $\begin{array}{l}\text { Emotional Exhaustion } \\
\text { High } \\
\text { Moderate } \\
\text { Low }\end{array}$ & $\begin{array}{l}47(43.7) \\
35(32.1) \\
27(24.8)\end{array}$ & $\begin{array}{l}47(42.7) \\
33(27.2) \\
30(30.0)\end{array}$ & 0.91 \\
\hline $\begin{array}{l}\text { Depersonalization } \\
\text { High } \\
\text { Moderate } \\
\text { Low }\end{array}$ & $\begin{array}{l}24(21.5) \\
42(36.8) \\
48(42.1)\end{array}$ & $\begin{array}{l}22(19.8) \\
33(29.7) \\
56(50.5)\end{array}$ & 0.41 \\
\hline $\begin{array}{l}\text { Personal Accomplishment } \\
\text { High } \\
\text { Moderate } \\
\text { Low }\end{array}$ & $\begin{array}{l}57(49.6) \\
38(33.0) \\
20(17.4)\end{array}$ & $\begin{array}{l}54(51.4) \\
32(30.5) \\
19(18.1)\end{array}$ & 0.93 \\
\hline Overall rate of STS & $60(50.9)$ & $48(42.5)$ & 0.24 \\
\hline Overall rate of Wellbeing & $115(93.0)$ & $105(97.5)$ & 0.13 \\
\hline
\end{tabular}

Almost half of the participants scored high $(42.9 \%)$ on the emotional exhaustion subscale and $20.2 \%$ scored high for depersonalization. $50.5 \%$ also scored high on the personal accomplishment scale. $52.4 \%$ of burned out physicians were female. One third of physicians at risk for burnout had 2 children, but the number of children did not correlate with an increased risk of burnout. No demographic factors were identified as a risk or a protective factor for the development of burnout.

\section{Secondary Traumatic Stress Scale}

STS was defined as a total score of $>38$. The rate of STS was $46.7 \%$ (Table 3 ). A higher total STSS score was noted for physicians practicing for $10-15$ years compared to those practicing for $5-10$ years $(p=0.04)$ with a higher score on the arousal subscale $(p=0.03)$. Physicians who followed a healthy diet had a lower total STS score $(p=0.01)$ and a lower score on all three subscales. The same group also seems to have higher scores on the wellbeing scale $(p=0.01)$.

\section{Personal Wellbeing Index}

A Personal Wellbeing Index score of $>35$ was defined as a positive score, which means that an individual was satisfied with his personal life. The overall rate of satisfaction was 95.3\% (Table 3). There was no significant difference for PWI scores for critical care and hematology/oncology physicians. With regard to hours of sleep per night, there was no 
significant difference in burnout or STS rate. However, physicians who slept $>7 \mathrm{~h}$ had a higher score on the PWI scale compared to those who sleep $3-5 \mathrm{~h}(\mathrm{p}=0.008)$ and $5-7 \mathrm{~h}$ $(p=0.02)$. Married physicians scored higher on the wellbeing scale compared to single physicians $(p=0.04)$. Neither the number of children nor any other lifestyle or demographic factors were associated with increased wellbeing.

\section{Discussion}

Our results demonstrate high rates of burnout and secondary traumatic stress in pediatric critical care and pediatric hematology/oncology physicians. This is consistent with recent studies showing that burn out starts during pediatrics residency (18). Fields et al studied burnout rates among PICU physicians 20 years ago and found a rate of $14 \%$, which is significantly lower than our findings. Garcia et al reported a burnout rate of $50 \%$ among general pediatricians and pediatric intensivists (19), in line with our findings. Burn out is not unique to Americans. Other studies have reported a rate of $41 \%$ at high risk for burnout among pediatric critical care physicians in Argentina (22). Interestingly, this study also found the highest rates among academic pediatricians working in a university setting. Comparing with other specialties, surgeons had similar rates of burnout, ranging from $39-41 \%(4)$.

Interestingly our study shows that physicians that are in practice for $>20$ years had higher scores on the depersonalization subscale. This is in contrast to prior studies that showed that physicians in the middle of their career (11-20 years in practice) are at the greatest risk for burnout (4). Another study by Downey et al assessed burnout among anesthesiologists and came to the conclusion that doctors who are 5-15 years in practice are at the greatest risk for burnout. In our study, physicians who are 10-15 years into their careers had higher secondary traumatic stress scores. Unfortunately, there is not much literature to compare our rates of secondary traumatic stress to and available data is mainly focused on military physicians (22).

We did find that a number of factors can mitigate burnout and STS rates. A healthy diet, sleep and religion positively influenced wellbeing and secondary traumatic stress rates. A subjectively healthy diet was associated with decreased total secondary traumatic stress scores and increased scored on the personal wellbeing scale. Consuming fruits and vegetables is associated with lower incidents of depression and higher rates of happiness and higher life satisfaction (23-25). Along with a healthy diet, more than 7 hours of sleep is also associated with physician wellbeing. It is well known that sleep deprivation is associated with decreased cognitive function, memory and reaction time (26).

Burnout poses a risk for the physician and the patient. High scores on the depersonalization and emotional exhaustion subscale are associated with alcohol abuse or dependence (27). Oreskovich et al. (28) sampled 25,073 surgeons, out of which $15.4 \%$ were identified to have an alcohol abuse disorder. Participants who were burned out (odds ratio, 1.25; $\mathrm{P}=.01$ ) and depressed (odds ratio, 1.48; $\mathrm{P}<.001$ ) were more likely to have alcohol abuse or dependence. Other studies have identified a 
correlation between burnout rates (specifically emotional exhaustion) and patient safety risks. Clinicians who scored high on the emotional exhaustion subscale of the MBI had higher standardized mortality ratios (29). A Mayo Clinic study also clearly linked burnout with self-perceived medical errors in both internal medicine residents and surgeons (30). In contrast, a recent study conducted in the adult ICU setting established that there is an increased rate of medical errors by depressed physicians, but burn out did not seem to correlate with an increase rate of medical errors (31). Another prospective cohort study done in three children's hospitals on pediatric residents have had similar results. (32). In our study we did not measure depression or assess for medical errors related with physician burnout. More studies are needed in the future to elicit if burnout leads to an increase rate of medical errors and the potential risks for the patients.

One important limitation of this study is that it was sent to members of the American Academy of Pediatrics, where $40.63 \%$ of the physicians are $>20$ years in practice. This could have skewed the outcomes. One limitation in our study may be that respondents to our survey could be those who are more likely to suffer from burnout and more likely to want to report their issues, or conversely, those most severely affected may have chosen not to participate. We also did not separately analyze burnout and STS against each other, and we presumed that the similar rates were in the same respondents, but that may not be accurate.

\section{Conclusion}

The rates of burnout and secondary traumatic stress are high in both pediatric critical care physicians and pediatric hematologist / oncologists. It may be that lifestyle factors, such as a healthy diet, sleep and exercise may serve as protective factors and increase overall wellbeing. Further studies need to be done to assess burnout, secondary traumatic stress rates among other pediatric subspecialties and to analyze proper coping mechanisms.

\section{References}

1. Schwenk TL. Physician well-being and the regenerative power of caring. JAMA. 2018 Apr 17;319(15):1543-4. [CrossRef] [PubMed]

2. AMA strongly supports the charter on physician well-being. March 29, 2018. Available at: www.ama-assn.org/ama-strongly-supports-charter-physician-well-being (accessed 6/14/19).

3. Berg S. Physician well-being again a burning topic in 2017. AMA. December 20, 2017. Available at: https://www.ama-assn.org/press-center/press-releases/amastrongly-supports-charter-physician-well-being (accessed 6/14/19).

4. Shanafelt TD, Boone S, Tan L, Dyrbye LN, Sotile W, Satele D, West CP, Sloan J, Oreskovich MR. Burnout and satisfaction with work-life balance among US physicians relative to the general US population. Arch Intern Med. 2012 Oct 8;172(18):1377-85. [CrossRef] [PubMed]

5. Maslach C, Jackson S. (1981). The Measurement of Experienced Burnout. Journal of Occupational Behaviour. 1981;2(2): 99-113. [CrossRef] [PubMed] 
6. Dyrbye LN, Varkey P, Boone SL, Satele DV, Sloan JA, Shanafelt TD. Physician satisfaction and burnout at different career stages. Mayo Clin Proc. 2013 Dec;88(12):1358-67. [CrossRef] [PubMed]

7. Richter A, Kostova P, Harth V, Wegner R. Children, care, career - a cross-sectional study on the risk of burnout among German hospital physicians at different career stages. J Occup Med Toxicol. 2014 Dec 3;9(1):41. [CrossRef] [PubMed]

8. Figley CR. Compassion Fatigue: toward a new understanding of the cost of caring. [book auth.] Secondary traumatic stress: self care issues for clinicians, researchers, and educators. Lutherville MD: Sidaran 1999.

9. Meadors P, Lamson A, Swanson M, White M, Sira N. Secondary traumatization in pediatric healthcare providers: compassion fatigue, burnout, and secondary traumatic stress. Omega (Westport). 2009-2010;60(2):103-28. [CrossRef] [PubMed]

10. Badger K, Royse D, Craig C. Hospital social workers and indirect trauma exposure: an exploratory study of contributing factors. Health Soc Work. 2008 Feb;33(1):63-71. [CrossRef] [PubMed]

11. Benuto LT, Yang Y, Ahrendt A, Cummings C. The secondary traumatic stress scale: Confirmatory factor analyses with a national sample of mental health social workers. Journal of Interpersonal Violence. March 11, 2018. [CrossRef] [PubMed]

12. Dominguez-Gomez E, Rutledge DN. Prevalence of secondary traumatic stress among emergency nurses.J Emerg Nurs. 2009 Jun;35(3):199-204. [CrossRef] [PubMed]

13. US Department of Health and Human Services, Office of Disease Prevention and Health Promotion. Healthy People 2020. Washington, D.C. Federal Government of the United States, 2010. Available at: https://www.healthypeople.gov/ (accessed $6 / 14 / 19)$.

14. Wheeler DL, Vassar M, Worley JA, Barnes LLB. A reliability generalization meta analysis of coefficient alpha for the Maslach burnout inventory. Educational and Psychological Measurement. 2011;71:231-44. [CrossRef]

15. Rafferty JP, Lemkau JP, Purdy RR, Rudisill JR. Validity of the Maslach Burnout Inventory for family practice physicians. J Clin Psychol. 1986 May;42(3):488-92. [CrossRef] [PubMed]

16. Chopra SS, Sotile WM, Sotile MO. STUDENTJAMA. Physician burnout. JAMA. 2004 Feb 4;291(5):633.[CrossRef] [PubMed]

17. Shanafelt TD, Bradley KA, Wipf JE, Back AL. Burnout and self-reported patient care in an internal medicine residency program. Ann Intern Med. 2002 Mar 5;136(5):35867. [PubMed]

18. Mahan JD. Burnout in pediatric residents and physicians: a call to action. Pediatrics. 2017 Mar;139(3). pii: e20164233. [CrossRef] [PubMed]

19. Garcia TT, Garcia PC, Molon ME, Piva JP, Tasker RC, Branco RG, Ferreira PE.Prevalence of burnout in pediatric intensivists: an observational comparison with general pediatricians. Pediatr Crit Care Med. 2014 Oct;15(8):e347-53. [CrossRef] [PubMed]

20. Bride BE, Robinson MM, Yegidis B, Figley CR. Development and validation of the secondary traumatic stress scale. Research on Social Work Practice. 2004; 14(1): 27-35. [PubMed] 
21. Personal Wellbeing Index- Adult, 5th Edition, 2013. International Wellbeing Group, Robert A Cummins, PhD, FAPsS, Deakin University, Australia

22. Galván ME, Vassallo JC, Rodríguez SP, et al. Professional burnout in pediatric intensive care units in Argentina. Arch Argent Pediatr. 2012 Dec;110(6):466-73. [CrossRef] [PubMed]

23. Kintzle S, Yarvis JS, Bride BE. Secondary traumatic stress in military primary and mental health care providers. Mil Med. 2013 Dec;178(12):1310-5. [CrossRef] [PubMed]

24. Conner TS, Brookie KL, Richardson AC, Polak MA. On carrots and curiosity: eating fruit and vegetables is associated with greater flourishing in daily life. $\mathrm{Br} \mathrm{J}$ Health Psychol. 2015 May;20(2):413-27. [CrossRef] [PubMed]

25. White BA, Horwath CC, Conner TS. Many apples a day keep the blues away--daily experiences of negative and positive affect and food consumption in young adults. Br J Health Psychol. 2013 Nov;18(4):782-98. [CrossRef] [PubMed]

26. Girbe F, Ramassamy C, Piton C, Costentin J. Ascorbic acid increases synaptosomal potassium-induced dopamine release. Neuroreport. 1994 May 9;5(9):1027-9. [CrossRef] [PubMed]

27. Jarral OA, Baig K, Shetty K, Athanasiou T. Sleep deprivation leads to burnout and cardiothoracic surgeons have to deal with its consequences. Int J Cardiol. 2015 Jan 20;179:70-2. [CrossRef] [PubMed]

28. Oreskovich MR, Kaups KL, Balch CM, Hanks JB, Satele D, Sloan J, Meredith C, Buhl A, Dyrbye LN, Shanafelt TD. Prevalence of alcohol use disorders among American surgeons. Arch Surg. 2012 Feb;147(2):168-74. [CrossRef] [PubMed]

29. Welp A, Meier LL, Manser T. Emotional exhaustion and workload predict clinicianrated and objective patient safety. Front Psychol. 2015 Jan 22;5:1573. [CrossRef] [PubMed]

30. West CP, Tan AD, Habermann TM, Sloan JA, Shanafelt TD. Association of resident fatigue and distress with perceived medical errors. JAMA. 2009 Sep 23;302(12):1294-300. [CrossRef] [PubMed]

31. Garrouste-Orgeas M, Perrin M, Soufir L, et al. The latroref study: medical errors are associated with symptoms of depression in ICU staff but not burnout or safety culture. Intensive Care Med. 2015 Feb;41(2):273-84. [CrossRef] [PubMed]

32. Fahrenkopf AM, Sectish TC, Barger LK, et al. Rates of medication errors among depressed and burnt out residents: prospective cohort study. BMJ. 2008 Mar 1;336(7642):488-91. [CrossRef] [PubMed] 